\title{
Aerosolised iloprost improves pulmonary haemodynamics in patients with primary pulmonary hypertension receiving continuous epoprostenol treatment
}

\author{
V Petkov, R Ziesche, W Mosgoeller, P Schenk, K Vonbank, L Stiebellehner, M Raderer, \\ Ch Brunner, M Kneussl, L H Block
}

\begin{abstract}
Background-Continuous intravenous treatment with epoprostenol significantly improves pulmonary haemodynamics and survival in patients with primary pulmonary hypertension (PPH). Its beneficial effect, however, may be blunted due to adverse effects such as catheter sepsis and systemic hypotension. Recent investigations have shown that inhaled iloprost is effective in the treatment of PPH. Based on their different pharmacokinetics, we hypothesised that the combination of intravenous epoprostenol and inhaled iloprost would be more efficacious than epoprostenol alone during acute testing in patients with PPH.
\end{abstract}

Methods-The effect of a single dose of inhaled iloprost (30 $\mu$ g total over 15 minutes) on pulmonary haemodynamics was examined in eight patients with PPH (initial non-responders to nitric oxide) who had considerable adverse effects during treatment with epoprostenol.

Results-The combination of inhaled iloprost and intravenous epoprostenol significantly improved mean pulmonary artery pressure (MPAP), cardiac index (CI), mixed venous oxygen saturation $\left(\mathrm{Svo}_{2}\right)$, and systemic arterial oxygen pressure $\left(\mathrm{PaO}_{2}\right)$ compared with epoprostenol treatment alone. Mean systemic arterial pressure (MSAP) and pulmonary capillary wedge pressure (PCWP) remained unchanged.

Conclusions-The pulmonary vasoreactivity shown by additional iloprost inhalation during effective epoprostenol treatment suggests that an improvement of treatment for pulmonary hypertension may be possible by combining vasoactive substances.

(Thorax 2001;56:734-736)

Keywords: epoprostenol; iloprost; primary pulmonary hypertension
Primary pulmonary hypertension $(\mathrm{PPH})$ is fatal disease causing progressive right heart failure within three years of diagnosis. ${ }^{1}$ Impairment of vascular and endothelial homeostasis is evidenced by a reduced synthesis of prostacyclin, increased thromboxane production, decreased formation of nitric oxide, and increased synthesis of endothelin-1. ${ }^{23}$ Prostacyclins such as epoprostenol, a potent vasodilator and inhibitor of both platelet aggregation and smooth muscle cell proliferation, are effective in the treatment of PPH. Although stereochemically different, the prostacyclin analogue iloprost and epoprostenol act via a prostacyclin receptor present in pulmonary artery smooth muscle cells. ${ }^{4}$ Pharmacokinetically, iloprost is more stable than epoprostenol with half lives of 30 minutes and 2 minutes, respectively. Both substances have been shown to improve pulmonary haemodynamics and survival in $\mathrm{PPH}$ when administered intravenously. ${ }^{5}$

The continuous intravenous administration of epoprostenol is associated with therapeutic problems such as systemic hypotension, catheter sepsis, gastrointestinal upsets, jaw pain, and headache. We have shown that epoprostenol treatment reverts initial nonresponsiveness to nitric oxide (NO), ${ }^{6}$ which suggests that pulmonary vasodilation may be incomplete in patients with PPH during treatment with epoprostenol. We have therefore examined whether additional inhalation of iloprost improves the pulmonary haemodynamics during continuous infusion of epoprostenol, given in a moderate to medium dose, in patients with stable PPH with side effects to the epoprostenol treatment such as systemic hypotension and severe headache.

\section{Methods}

PATIENTS

Eight patients with PPH were investigated after a mean treatment period with epoprostenol (Flolan, GlaxoWellcome Ltd, Uxbridge, UK) of 18 months (range 4-28 months). Epoprostenol had been given as a result of nonresponsiveness to acute testing with NO (table 1). Each patient gave written informed consent 


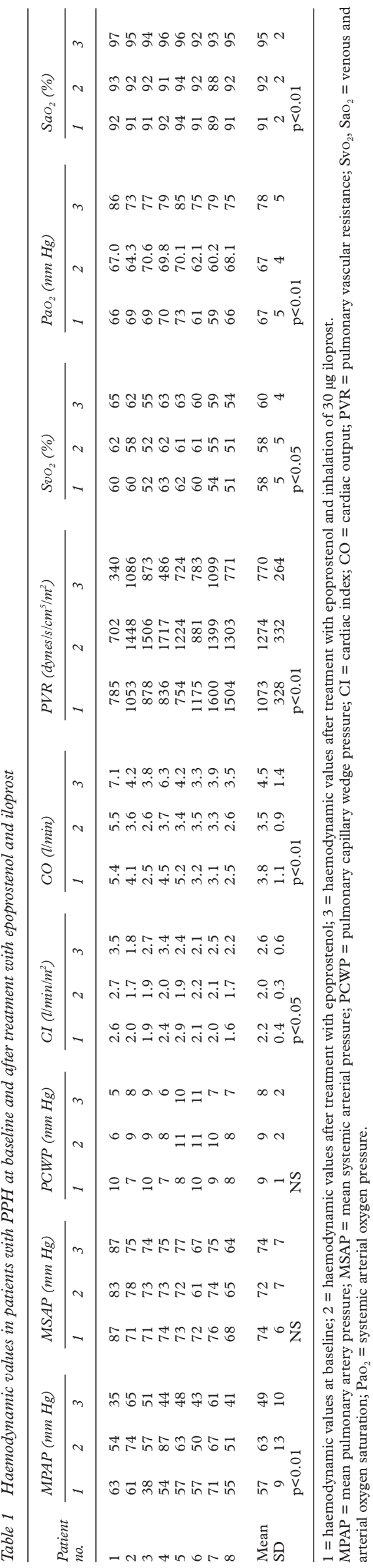

to participate in the study which was approved by the ethical committee of the University of Vienna. The diagnosis of PPH was based on a raised MPAP of $>30 \mathrm{~mm} \mathrm{Hg}$ and the diagnostic criteria published by Rich et al. ${ }^{7}$ In contrast to the initial lack of vasoreactivity to NO, after treatment with epoprostenol all patients had a positive vasodilator response to $\mathrm{NO}(>10 \%$, 20 ppm NO). The patients had stable pulmonary haemodynamics, although maximum doses were not achieved due to adverse effects such as systemic hypotension and severe headache.

Iloprost (Ilomedin, Schering AG, Berlin, Germany; $30 \mu \mathrm{g}$ ) was inhaled for 15 minutes via the MicroDrop Master Jet (MPV, Truma, Germany) using a particle size of $3 \mu \mathrm{m}$ to provide alveolar deposition of the substance. Pulmonary haemodynamics and gas exchange were measured before and 15 minutes after inhalation of iloprost while permanently delivering epoprostenol into the subclavian vein as described previously ${ }^{8}$ using a portable pump system (CADD-1, Pharmacia-Upjohn, Vienna, Austria). Right heart catheterisation was performed as previously reported. ${ }^{6}$

STATISTICAL ANALYSIS

Data were analysed descriptively using the IDV-Module Report 6.0.08 and statistically with the IDV-Module Testimate 5.2a. Baseline demographic and haemodynamic variables were recorded and are presented as mean (SD). Intraindividual comparison of the haemodynamic variables measured at baseline and after inhalation with iloprost was made using the two sided Wilcoxon $U$ test for paired data. $\mathrm{p}$ values below 0.05 were considered statistically significant.

\section{Results}

The effect of simultaneous inhalation of iloprost ( $30 \mu \mathrm{g}$ within 15 minutes) on pulmonary haemodynamics was tested in eight patients (two men) with a proven diagnosis of PPH continuously receiving intravenous epoprostenol (dose range $12-30 \mathrm{ng} / \mathrm{min} / \mathrm{kg}$, mean $20 \mathrm{ng} / \mathrm{min} / \mathrm{kg}$ ) for a mean period of 18 months. Before inhalation of iloprost the mean (SD) pulmonary artery pressure (MPAP) was 63 (13) $\mathrm{mm} \mathrm{Hg}$, cardiac index (CI) 2.0 (0.3) 1/ $\mathrm{min} / \mathrm{m}^{2}$, pulmonary vascular resistance (PVR) 1274 (332) dyne $/ \mathrm{s} / \mathrm{cm}^{5}$, pulmonary capillary wedge pressure (PCWP) 9 (2) $\mathrm{mm} \mathrm{Hg}$, systemic arterial oxygen tension $\left(\mathrm{PaO}_{2}\right) 67$ (4) $\mathrm{mm} \mathrm{Hg}$, and mixed venous oxygen saturation $\left(\mathrm{SvO}_{2} \%\right) 58$ (5)\%. Addition of $30 \mu \mathrm{g}$ inhaled iloprost to continuous epoprostenol improved pulmonary haemodynamics in all patients. MPAP decreased to 49 (10) $\mathrm{mm} \mathrm{Hg}$ $(\mathrm{p}<0.01)$ and PVR to 770 (264) dyne $/ \mathrm{s} / \mathrm{cm}^{5}$ $(\mathrm{p}<0.01)$. CI increased to $2.51 / \mathrm{min} / \mathrm{m}^{2}$ ( $\mathrm{p}<0.05), \mathrm{PaO}_{2}$ to 78 (5) $\mathrm{mm} \mathrm{Hg}(\mathrm{p}<0.01)$, and $\mathrm{SvO}_{2}$ to $60(4) \%(\mathrm{p}<0.05)$ compared with epoprostenol alone. Systemic blood pressure and PCWP did not change significantly (table 1).

\section{Discussion}

The combination of continuous intravenous treatment with epoprostenol and a 15 minute 
inhalation of aerosolised iloprost significantly improved pulmonary haemodynamics in eight patients with severe PPH. More importantly, the combination of both drugs improved parameters closely linked to long term effectiveness of treatment and survival in $\mathrm{PPH}$ such as $\mathrm{SvO}_{2}, \mathrm{MPAP}$, and CI. ${ }^{5} 9$ The addition of iloprost to a continuous infusion of epoprostenol did not result in systemic hypotension or local undesired effects.

These results suggest that epoprostenol at a submaximal dose allows for stable treatment of $\mathrm{PPH}$. Moreover, it provides additional evidence for the fact that continuous epoprostenol treatment regains, at least in part, pulmonary vasodilatation. In addition, this study shows that the increased vasodilatory effect can be achieved by adding a substance with comparable pharmacology, but different pharmacokinetics and a different route of application. Furthermore, it raises the possibility that the combination of prostacyclin treatment with vasodilators representing a different pharmacological approach (such as PDE5 inhibitors) may circumvent the need for maximum dosing of epoprostenol with its undesirable side effects.

1 D'Alonzo GE, Barst RJ, Ayres SM, et al. Survival in patients with primary pulmonary hypertension. Results from a national prospective registry. Ann Intern Med 1991;115:343-9.

2 Christman BW, McPherson CD, Newman JH, et al. An imbalance between the excretion of thromboxane and Engl f Med 1992;327:70-5.

3 Giaid A, Saleh D. Reduced expression of endothelial nitric oxide synthase in the lungs of patients with pulmonary hypertension. N Engl f Med 1995;333:214-21.

4 Olschewski H, Walmrath D, Schermuly R, et al. Aerosolized prostacyclin and iloprost in severe pulmonary hyperprostacyclin and iloprost in severe pulm

5 Higenbottam T, Butt AY, McMahon A, et al. Long-term intravenous prostaglandin (epoprostenol or iloprost) for treatment of severe pulmonary hypertension. Heart 1998; 80:151-5.

6 Ziesche R, Petkov V, Wittmann K, et al. Treatment with epoprostenol reverts nitric oxide non-responsiveness in patients with primary pulmonary hypertension. Heart 2000;83:406-9.

7 Rich S, Dantzker DR, Ayres SM, et al. Primary pulmonary hypertension. A national prospective study. Ann Intern Med 1987;107:216-23.

8 Barst RJ, Rubin LJ, Long WA, et al. A comparison of continuous intravenous epoprostenol (prostacyclin) with conventional therapy for primary pulmonary hypertension. The Primary Pulmonary Hypertension Study Group. $N$ Engl f Med 1996;334:296-302.

9 Rubin LJ. Primary pulmonary hypertension. N Engl f Med 1997;336:111-7.

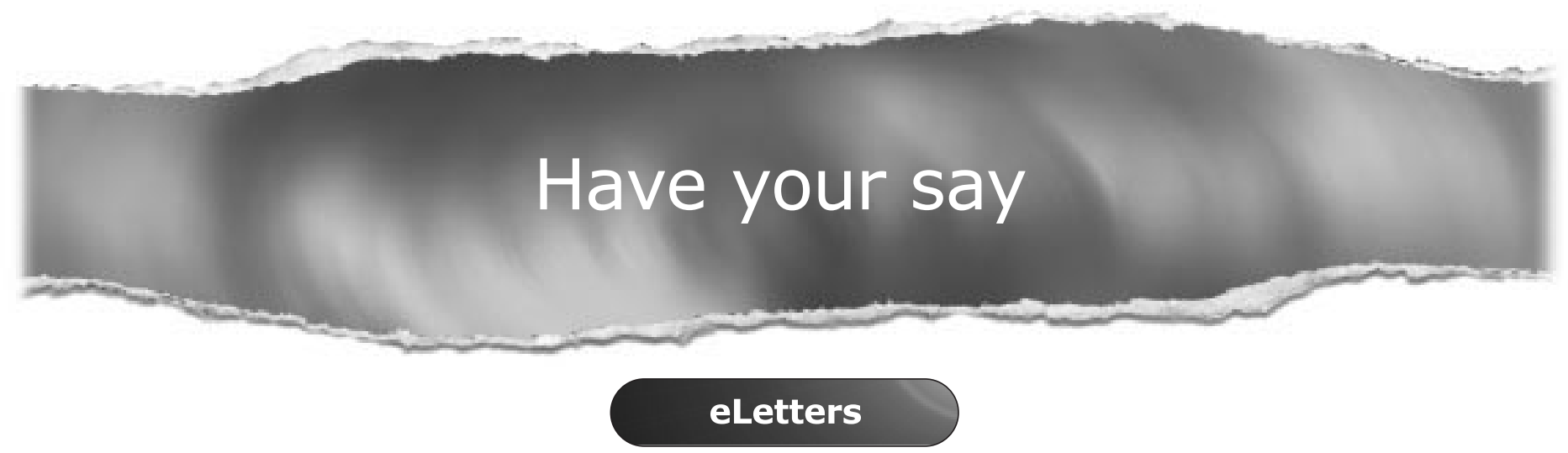

If you wish to comment on any article published in Thorax you can send an eLetter using the eLetters link at the beginning of each article. Your response will be posted on Thorax online within a few days of receipt (subject to editorial screening).

www.thoraxjnl.com 